\title{
Refractive index evolution of various commercial acrylic resins during photopolymerization
}

\author{
F. Aloui, L. Lecamp*, P. Lebaudy, F. Burel \\ Normandie Université, INSA de Rouen, CNRS UMR 6270, FR 3038, Avenue de l'Université, F-76801 Saint Etienne \\ du Rouvray Cedex, France
}

Received 12 April 2018; accepted in revised form 2 June 2018

\begin{abstract}
A set of commercial (meth)acrylic resins was photopolymerized under identical irradiation conditions and evolution of their refractive index was monitored as a function of double bond conversion. Initial refractive index values ranged from 1.4445 to 1.5454 and then linearly increased with conversion as long as the material was not in the glassy state. This increase was related to an increase of the material density arising during polymerization. Final refractive index values ranged from 1.4804 to 1.5632 . The knowledge of the refractive index and of its evolution during the photocuring is indispensable, in particularly to elaborate composite materials (polymer matrix + filler) with well controlled optical properties.
\end{abstract}

Keywords: industrial applications, photopolymerization, acrylic resin, refractive index

\section{Introduction}

Nowadays, acrylic materials are widely present in various application fields and many commercial resins are available on the market. If these acrylic resins are currently used to elaborate photocured materials, they can also be mixed with (in)organic fillers to obtain composite materials for dental applications [1-4], paints [5, 6], ceramics [7-10]. The main shortcoming of the photopolymerization process applied to composite formulations is the low depth of cure due to the limited light penetration resulting from scattering by fillers and filler-matrix interface. Theoretical and experimental results have shown that matching filler and organic matrix refractive indices leads to a decrease in the light scattering phenomenon [11-14]. Because of the acrylic matrix volume shrinkage consecutive to its photopolymerization, it is noteworthy that the refractive index of this matrix increases, whereas the refractive index of filler is supposed to be constant. If the refractive index of (meth)acrylic resins is often known, its evolution during their polymerization is never specified in the technical datasheets. However, these data are essential for applications in need of well controlled optical properties (holographic data-storage (HDS) technologies [15], transparent glass cloth reinforced plastics [16], gradient-index (GRIN) optics [17], transparent fiber glass reinforced composites [18] etc), as well as for the elaboration of thick homogeneous composite materials, where the prediction of the cure light transmission evolution and its influence on conversion profiles and cure depth is fundamental [19].

This work aims to characterize the refractive index evolution of some usual and commercial photocurable (meth)acrylic resins. For that, refractive index, double bond conversion, mechanical transition temperature $T_{\alpha}$ and material density were measured versus irradiation time. The paper will be decomposed in two parts. In the first part, an aromatic dimethacrylate resin (Bis-GMA) was chosen to accurately describe the experimental process used. In the second 
part, results obtained on the set of commercial resins were discussed.

\section{Materials and methods}

\subsection{Materials}

Tripropylene glycol diacrylate (TPGDA, SigmaAldrich), triethylene glycol dimethacrylate (TEGDMA, Sigma-Aldrich, 95\%), polyethylene glycol (200) dimethacrylate (PEG200DMA, Sigma Aldrich), pentaerythritol triacrylate (PETA, SigmaAldrich), Bisphenol A glycidyl dimethacrylate (BisGMA, Sigma-Aldrich, 99\%) were used as received. Photomer 5429, Photomer 3015 and Photomer 3016 were kindly supplied by IGM Resins (Cognis). Crodamer UVP215 and Crodamer (UVP220) were purchased from ex-Croda. Ebecryl 836, Ebecryl 851, Ebecryl 1608, Ebecryl 605 and Ebecryl 3700 were kindly supplied by UCB Chemicals. Dipropylene glycol diacrylate (DPGDA), ethoxylated 3 bisphenol A dimethacrylate (BPA3EODMA), CN104C75 and CN104Y50 were kindly supplied by Sartomer. Laromer 8800, Laromer 8986 and Irgacure 819 were kindly supplied by BASF. All these resins were used as received.

$1 \mathrm{wt} \%$ Irgacure 819 was added in each resin and the mixture was stirred at room temperature.

\subsection{Methods}

\subsubsection{Conversion and refractive index measurements}

The polymerization progress was monitored at $30^{\circ} \mathrm{C}$ by real time infrared spectroscopy using a Vertex 70 FTIR spectrometer (Bruker). An attenuated total reflection accessory (ATR MKII Golden Gate, Specac, Eurolabo) was used. A drop of the photocurable mixture was spread out over the ATR crystal and covered by a polyethylene film and a quartz plate in order to assure uniform exposed surface and to avoid the reaction inhibition caused by oxygen. The absorbance measured for each functional group was determined by the area $(A)$ of the corresponding absorption peak. The conversion $\chi$ was then calculated using the ratios of the (meth)acrylic double bond absorbance ( $A^{\text {function }) ~ a t ~} 1636$ or $809 \mathrm{~cm}^{-1}$ to the reference absorbance $\left(A^{\text {ref }}\right)$ corresponding to the aromatic cycle at $1607 \mathrm{~cm}^{-1}$ for aromatic resins or to the $\mathrm{C}-\mathrm{O}$ band at $1452 \mathrm{~cm}^{-1}$ for aliphatic resins according to Equation (1):
$\chi(t)=\frac{\frac{A_{0}^{\text {function }}}{A_{0}^{\text {ref }}}-\frac{A_{t}^{\text {function }}}{A_{t}^{\text {ref }}}}{\frac{A_{0}^{\text {function }}}{A_{0}^{\text {ref }}}}$

where $A_{0}$ is the initial area and $A_{\mathrm{t}}$ is the area of the peak at $t$ time.

The refractive index evolution was followed at $30^{\circ} \mathrm{C}$ by real time refractometry at $656 \mathrm{~nm}$ using an Arago refractometer (Cordouan Technologies). The formulation was spread out over the Sapphire prism without adding any high refractive index interfacial contact agent.

The light intensity coming from a $365 \mathrm{~nm}$ light emitting diode was measured at the sample surface using a radiometer (Vilber - Intraspec Oriel VLX-3W).

\subsubsection{Density measurement}

Material density was measured at $20^{\circ} \mathrm{C}$ with an Archimedean balance (Scaltec analytical balance fitted with a density determination kit appropriate to an accuracy to $10^{-4} \mathrm{~g}$ ).

\subsubsection{Mechanical transition temperature measurement}

Photocured samples were analyzed by dynamical mechanical analysis (DMA Q800, TA Instruments) in compression mode using a stainless steel parallel plate probe at a $1 \mathrm{~Hz}$ frequency and a $3{ }^{\circ} \mathrm{C} / \mathrm{min}$ heating rate. The applied strain amplitude was $5 \mu \mathrm{m}$. The mechanical transition temperature $T_{\alpha}$ was measured at the maximum of the $\tan \delta$ curve.

\section{Results and discussion}

\subsection{Description of the experimental process}

Bis-GMA was first irradiated with a $20 \mathrm{~mW} \cdot \mathrm{cm}^{-2}$ light intensity in the presence of $1 \mathrm{wt} \%$ Irgacure 819. The photopolymerization reaction was monitored in real time by infrared spectroscopy and refractometry. Figure 1 shows that the refractive index value evolved versus time in the same way that double bond conversion.

In a general way, the refractive index value of a given material depends on two parameters: the material density and its polarisability [20]. However, it is well known that, in the course of the photopolymerization, the volume shrinkage increases the material density, whereas the polarisability of the molecule decreases (evolution from a double carbon-carbon 


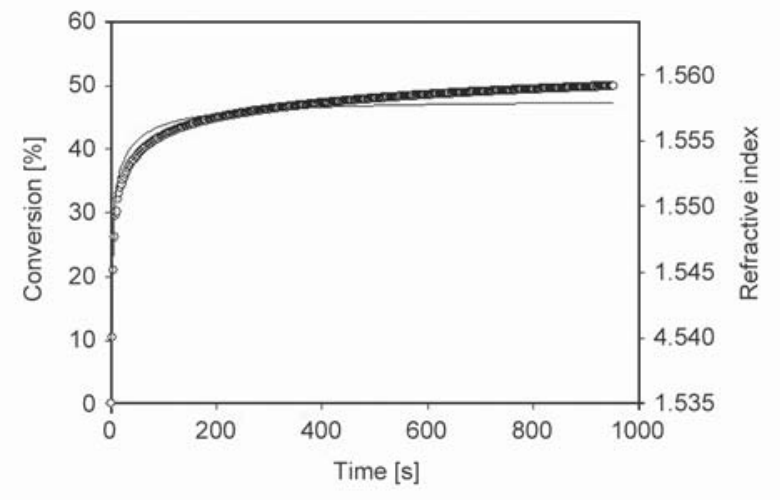

Figure 1. (-) refractive index and (o) double bond conversion of Bis-GMA versus irradiation time $(T=$ $30{ }^{\circ} \mathrm{C}-I_{0}=20 \mathrm{~mW} \cdot \mathrm{cm}^{-2}$ ).

bond towards single carbon-carbon bond). Hence, the evolution of the two parameters modify the refractive index value of the reaction mixture in an antagonist way. Experimental results revealed an increase in the refractive index value, meaning that the material density prevailed over the polarisability, as already mentioned [11, 14, 21-23]. The evolution of the material density versus double bond conversion was measured to confirm this assumption (Figure 2).

The combination of both refractive index and conversion evolution curves by elimination of the time parameter allowed plotting the relationship between conversion and refractive index in the course of the UV exposure (Figure 3). One can observe that linear relationships was obtained at conversion lower than $40 \%$. Above this value, the reaction continued but the refractive index remained constant. This can be related to the material density evolution (Figure 2). Indeed, the density of BisGMA, as its refractive index, became constant when conversion reached $40 \%$. Let us remind that

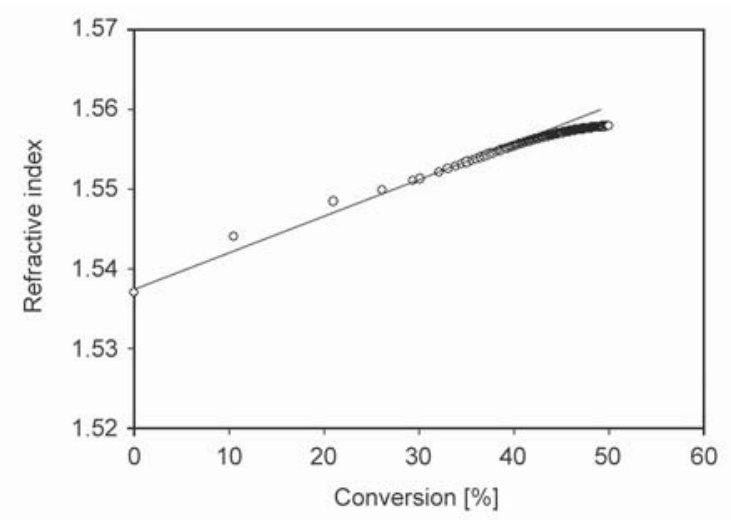

Figure 2. Refractive index-conversion relationship for Bis$\operatorname{GMA}\left(T=30^{\circ} \mathrm{C}-I_{0}=20 \mathrm{~mW} \cdot \mathrm{cm}^{-2}\right)$.

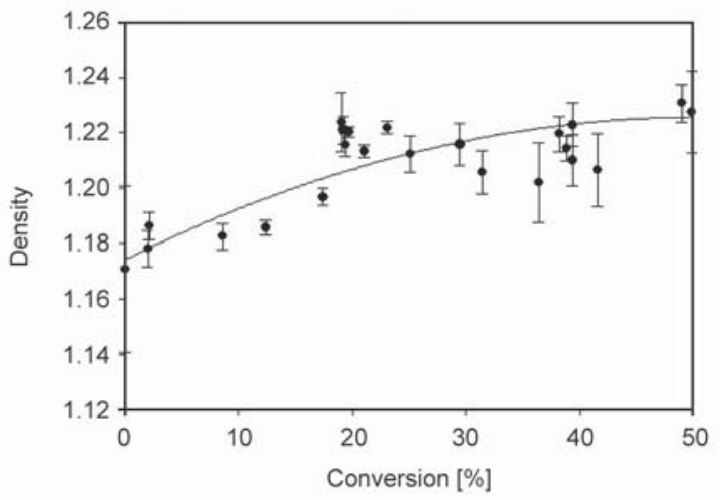

Figure 3. Density-conversion relationship for Bis-GMA $(T=$ $30^{\circ} \mathrm{C}-I_{0}=20 \mathrm{~mW} \cdot \mathrm{cm}^{-2}$ ).

the maximal double bond conversion is limited by the material vitrification [24].

\subsection{Discussion of the physicochemical characteristics of commercial resins}

Several resins belonging to three great families of acrylic resins were selected: ether acrylates, polyester acrylates and epoxy acrylates (Table 1). Each one was photopolymerized in the presence of $1 \mathrm{wt} \%$ Irgacure 819 with a $200 \mathrm{~mW} \cdot \mathrm{cm}^{-2} \mathrm{UV}$ light intensity and photocured materials were analyzed by infrared spectroscopy, refractometry and DMA. Final double bond conversion, initial and final refractive indices and mechanical transition temperature $T \alpha$ of the materials are collected on Figure 4 and Table 1.

Firstly, one can observe that, before photopolymerization, the initial refractive index value of (meth)acrylic resins is ranging from 1.4445 and 1.5454. As aforementioned, the intrinsic refractive index of a resin depends on its density and on its chemical structure (nature of atoms and chemical bonds), and more especially, on the polarisability of the molecule [20]. Thus, the contribution of simple covalent bond to the molecule polarisability is lower than the contribution of aromatic rings [25]. This is the reason why the lower values were obtained for aliphatic resins and the higher for aromatic ones.

Moreover, the refractive index increase consecutive to the polymerization reaction is greater for ether acrylates ( $\Delta n$ from 0.035 to 0.051 for aliphatic resins with final double bond conversion ranging from 63 to $87 \%-\Delta n$ about 0.027 for aromatic resins with final double bond conversion ranging from 50 to $62 \%$ ) than for polyester acrylates ( $\Delta n$ from 0.019 to 0.027 with final double bond conversion ranging from 42 to $100 \%$ ) and epoxy acrylates ( $\Delta n$ from 0.016 to 0.024 with final double bond conversion 
Table 1. Physicochemical characteristics of commercial (meth)acrylic resins before and after photopolymerization $\left(I_{0}=200 \mathrm{~mW} \cdot \mathrm{cm}^{-2}\right)$.

\begin{tabular}{|c|c|c|c|c|c|c|c|c|}
\hline \multirow{2}{*}{$\begin{array}{l}\text { Commercial name } \\
\text { (purchaser) }\end{array}$} & \multirow{2}{*}{$\begin{array}{l}\text { Chemical } \\
\text { composition }\end{array}$} & \multirow{2}{*}{$\begin{array}{c}\text { Molar } \\
\operatorname{mass}^{(a)} \\
{\left[\mathrm{g} \cdot \mathrm{mol}^{-1}\right]}\end{array}$} & \multirow{2}{*}{$\begin{array}{c}\text { Density }^{(a)} \\
\text { at } 25^{\circ} \mathrm{C}\end{array}$} & \multicolumn{3}{|c|}{ Refractive index $^{(\mathbf{b})}$ at $656 \mathrm{~nm}$} & \multirow{2}{*}{$\begin{array}{c}\text { Double bond } \\
\text { conversion }^{(\mathrm{c})} \\
{[\%]}\end{array}$} & \multirow{2}{*}{$\begin{array}{l}T_{\alpha}^{(d)} \\
{\left[{ }^{\circ} \mathrm{C}\right]}\end{array}$} \\
\hline & & & & Before UV & After UV & $\Delta n$ & & \\
\hline \multicolumn{9}{|c|}{ Ether acrylates } \\
\hline $\begin{array}{l}\text { DPGDA / SR } 508 \\
\text { (Sartomer) }\end{array}$ & $\begin{array}{c}\text { Dipropylene glycol } \\
\text { diacrylate }\end{array}$ & 242 & 1.05 & 1.4445 & 1.4858 & 0.0358 & 86 & 45 \\
\hline $\begin{array}{l}\text { TPGDA } \\
\text { (Sigma-Aldrich) }\end{array}$ & $\begin{array}{c}\text { Tripropylene glycol } \\
\text { diacrylate }\end{array}$ & 300 & 1.03 & 1.4458 & 1.4804 & 0.0346 & 87 & 54 \\
\hline $\begin{array}{l}\text { TEGDMA } \\
\text { (Sigma-Aldrich) }\end{array}$ & $\begin{array}{l}\text { Triethylene glycol } \\
\text { dimethacrylate }\end{array}$ & 286 & 1.09 & 1.4552 & 1.5066 & 0.0514 & 85 & 145 \\
\hline $\begin{array}{l}\text { PEG200DMA } \\
\text { (Sigma-Aldrich) }\end{array}$ & $\begin{array}{l}\text { Polyethylene glycol } \\
\text { (200) dimethacrylate }\end{array}$ & 330 & 1.08 & 1.4553 & 1.5003 & 0.0450 & 87 & 120 \\
\hline $\begin{array}{l}\text { PETA } \\
\text { (Sigma-Aldrich) }\end{array}$ & $\begin{array}{c}\text { Pentaerythritol } \\
\text { triacrylate }\end{array}$ & 298 & 1.16 & 1.4776 & 1.5134 & 0.0358 & 63 & 122 \\
\hline $\begin{array}{l}\text { BPA3EODMA / SR 348C } \\
\text { Sartomer) }\end{array}$ & $\begin{array}{c}\text { Ethoxylated } 3 \\
\text { bisphenol A } \\
\text { dimethacrylate }\end{array}$ & 496 & 1.12 & 1.5269 & 1.5543 & 0.0275 & 62 & 91 \\
\hline $\begin{array}{l}\text { Bis-GMA } \\
\text { (Sigma-Aldrich) }\end{array}$ & $\begin{array}{l}\text { Bisphenol A glycidyl } \\
\text { dimethacrylate }\end{array}$ & 512 & 1.16 & 1.5369 & 1.5632 & 0.0263 & 50 & 55 \\
\hline \multicolumn{9}{|c|}{ Polyester acrylates } \\
\hline $\begin{array}{l}\text { Photomer } 5429 \\
\text { (Cognis) }\end{array}$ & $\begin{array}{c}\text { Tetrafunctional } \\
\text { polyester acrylate } \\
\text { oligomer }\end{array}$ & - & - & 1.4561 & 1.4839 & 0.0278 & 100 & 40 \\
\hline $\begin{array}{l}\text { Laromer } 8800 \\
\text { (BASF) }\end{array}$ & $\begin{array}{l}\text { Modified polyester } \\
\text { acrylate }\end{array}$ & - & 1.20 & 1.4884 & 1.5099 & 0.0216 & 94 & 63 \\
\hline $\begin{array}{l}\text { CR UVP-215 } \\
\text { (Croda) }\end{array}$ & Polyester acrylate & - & - & 1.4946 & 1.5153 & 0.0207 & 91 & 20 \\
\hline $\begin{array}{l}\text { CR UVP-220 } \\
\text { (Croda) }\end{array}$ & Polyester acrylate & - & - & 1.4992 & 1.5179 & 0.0187 & 77 & 45 \\
\hline $\begin{array}{l}\text { Ebecryl } 851 \\
\text { (UCB Chemicals) }\end{array}$ & $\begin{array}{c}\text { Polyester acrylate } \\
(f=2.5)\end{array}$ & - & 1.12 & 1.5071 & 1.5337 & 0.0266 & 42 & 90 \\
\hline $\begin{array}{l}\text { Ebecryl } 836 \\
\text { (UCB Chemicals) }\end{array}$ & $\begin{array}{l}\text { Polyester hexaacrylate } \\
\quad+25 \% \text { DPGDA }\end{array}$ & - & - & 1.4920 & 1.5138 & 0.0218 & 63 & 145 \\
\hline \multicolumn{9}{|c|}{ Epoxy acrylates } \\
\hline $\begin{array}{l}\text { Laromer } 8986 \\
\text { (BASF) }\end{array}$ & $\begin{array}{l}\text { Modified aromatic } \\
\text { epoxy acrylate }\end{array}$ & - & 1.20 & 1.5059 & 1.5298 & 0.0239 & 45 & 87 \\
\hline $\begin{array}{l}\text { CN104Y50 } \\
\text { (Sartomer) }\end{array}$ & $\begin{array}{c}\text { Bisphenol A epoxy } \\
\text { diacrylate }+ \\
50 \% \text { ethoxylated } 5 \\
\text { pentaerythritol } \\
\text { tetraacrylate (PPTTA) }\end{array}$ & 900 & - & 1.5075 & 1.5319 & 0.0244 & 57 & 75 \\
\hline $\begin{array}{l}\text { Ebecryl } 605 \\
\text { (UCB Chemicals) }\end{array}$ & $\begin{array}{c}\text { Standard Bisphenol A } \\
\text { epoxy acrylate + } \\
25 \% \text { TPGDA }\end{array}$ & - & 1.17 & 1.5174 & 1.5394 & 0.0219 & 60 & 79 \\
\hline $\begin{array}{l}\text { CN104C75 } \\
\text { (Sartomer) }\end{array}$ & $\begin{array}{c}\text { Bisphenol A epoxy } \\
\text { diacrylate }+25 \% \\
\text { TPGDA }\end{array}$ & 900 & - & 1.5277 & 1.5473 & 0.0196 & 76 & 116 \\
\hline $\begin{array}{l}\text { Photomer } 3016 \\
\text { (Cognis) }\end{array}$ & $\begin{array}{c}\text { Bisphenol A epoxy } \\
\text { diacrylate }\end{array}$ & 452 & - & 1.5305 & 1.5509 & 0.0204 & 56 & 107 \\
\hline $\begin{array}{l}\text { Ebecryl } 1608 \\
\text { (UCB Chemicals) }\end{array}$ & $\begin{array}{c}\text { Standard Bisphenol A } \\
\text { epoxy diacrylate }+ \\
15 \% \text { propoxylated } \\
\text { glycerol triacrylate } \\
\text { (PPGTA) }\end{array}$ & - & 1.17 & 1.5312 & 1.5483 & 0.0171 & 49 & 75 \\
\hline $\begin{array}{l}\text { Photomer } 3015 \\
\text { (Cognis) }\end{array}$ & $\begin{array}{c}\text { Bisphenol A epoxy } \\
\text { diacrylate }\end{array}$ & - & - & 1.5321 & 1.5509 & 0.0188 & 62 & 39 \\
\hline $\begin{array}{l}\text { Ebecryl } 3700 \\
\text { (UCB Chemicals) }\end{array}$ & $\begin{array}{l}\text { Standard Bisphenol A } \\
\text { epoxy diacrylate }\end{array}$ & 524 & 1.17 & 1.5454 & 1.5613 & 0.0160 & 44 & 107 \\
\hline
\end{tabular}

- = not specified; ${ }^{(\mathrm{a})}$ commercial data; ${ }^{(\mathrm{b})}$ measured by FTIR spectroscopy; ${ }^{(\mathrm{c})}$ measured by refractometry; ${ }^{(\mathrm{d})}$ measured by DMA 


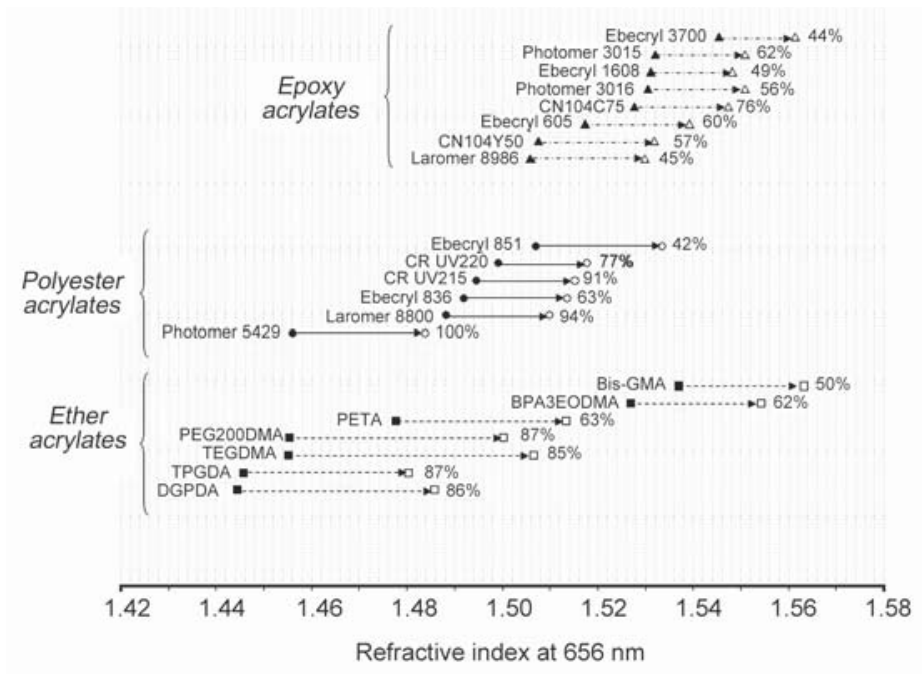

Figure 4. Evolution of the refractive index value of commercial (meth)acrylic resins before $(\bullet)$ and after (o) photopolymerization $\left(T=30^{\circ} \mathrm{C}-I_{0}=20 \mathrm{~mW} \cdot \mathrm{cm}^{-2}-\right.$ double bond conversion [\%] at the end of reaction is specified).

ranging from 44 to $76 \%$ ). It can be also noted that, comparing the different difunctional ether acrylate resins, the higher the resin molecular mass, the lower the refractive index variation after polymerization. Regardless of ultimate double bond conversion, all these results are in accordance with the fact that the volume shrinkage is usually higher in the case of 'small' aliphatic molecules compared to 'big' aromatic ones [2].

In the case of multi-components systems, each component contributes to the refractive index value of the formulation. Thus, the refractive index of binary mixtures can be calculated by the sum of refractive index of each component weighted by its mass or molar fraction [12]. Within this framework, it is interesting to compare the materials obtained from standard Bisphenol A epoxy diacrylate (Ebecryl 3700, Ebecryl 605 and Ebecryl 1608). As expected, adding reactive diluent such as PPGDA (Ebecryl 1608) or TPGDA (Ebecryl 605) allowed reaching higher final double bond conversion (49\% for Ebecryl 1608 and $60 \%$ Ebecryl 605) because of lower mechanical transition temperature $\left(T_{\alpha}=75^{\circ} \mathrm{C}\right.$ for Ebecryl 1608 and $T_{\alpha}=79^{\circ} \mathrm{C}$ for Ebecryl 605) compared to the pure resin (44\% and $T_{\alpha}=107^{\circ} \mathrm{C}$ for Ebecryl 3700). The consequence was a greater refractive index increase during the photopolymerization of diluted resins (0.0219 for Ebecryl 605 against 0.0160 for Ebecryl $3700)$. Hence, adding a reactive diluent had two effects: first, a shift of the formulation refractive index towards lower values; second, an increase in the refractive index gap $(\Delta n)$ resulting from the enhancement of the final double bond conversion and consequently, higher volume shrinkage and material density.

\section{Conclusions}

Results presented in this paper are not trivial in literature. However, these ones are indispensable both for some targeted applications and for enhancing the photopolymerization process applied to thick composite materials. For example, the only way to obtain an optically transparent composite material is that refractive indices of both filler and final photopolymerized matrix match. As well, to obtain thick homogeneous composite material, the knowledge of the UV light intensity inside the medium and its evolution requires knowing the evolution of refractive indices during the process implementation.

\section{References}

[1] Bayou S., Mouzali M., Aloui F., Lecamp L., Lebaudy P.: Simulation of conversion profiles inside a thick dental material photopolymerized in the presence of nanofillers. Polymer, 45, 863-870 (2013).

https://doi.org/10.1038/pj.2012.226

[2] Vreven J., Raskin A., Sabbagh J., Vermeersch G., Leloup G.: Résines composites (in French). EMCOdontologie, 23-065-E-10 (2005).

[3] Ferracane J. L.: Resin composite-State of the art. Dental Materials, 27, 29-38 (2011). https://doi.org/10.1016/j.dental.2010.10.020

[4] Liu F., Jiang X., Zhang Q., Zhu M.: Strong and bioactive dental resin composite containing poly(bis-GMA) grafted hydroxyapatite whiskers and silica nanoparticles. Composites Science and Technology, 101, 86-93 (2014).

https://doi.org/10.1016/j.compscitech.2014.07.00 
[5] Kardar P., Ebrahimi M., Bastani S.: Influence of temperature and light intensity on the photocuring process and kinetics parameters of a pigmented UV curable system. Journal of Thermal Analysis and Calorimetry, 118, 541-549 (2014).

https://doi.org/10.1007/s10973-014-3984-Z

[6] Macarie L., Ilia G.: Influence of pigment properties on UV-curing efficiency. Journal of Applied Polymer Science, 104, 247-252 (2007).

https://doi.org/10.1002/app.25563

[7] Chartier T., Badev A., Abouliatim Y., Lebaudy P., Lecamp L.: Stereolithography process: Influence of the rheology of silica suspensions and of the medium on polymerization kinetics - Cured depth and width. Journal of the European Ceramic Society, 32, 1625-1634 (2012).

https://doi.org/10.1016/j.jeurceramsoc.2012.01.010

[8] Badev A., Abouliatim Y., Chartier T., Lecamp L., Lebaudy P., Chaput C., Delage C.: Photopolymerization kinetics of a polyether acrylate in the presence of ceramic fillers used in stereolithography. Journal of Photochemistry and Photobiology A: Chemistry, 222, 117 122 (2011).

https://doi.org/10.1016/j.jphotochem.2011.05.010

[9] Bae C-J., Halloran J. W.: Integrally cored ceramic mold fabricated by ceramic stereolithography. International Journal of Applied Ceramic Technology, 8, 255-262 (2011).

https://doi.org/10.1111/j.1744-7402.2010.02568.x

[10] Lee J. H., Prud'homme R. K., Aksay I. A.: Processing of organic/inorganic composites by stereolithography. Material Research Society Symposium - Proceedings, 625, 165-172 (2000).

https://doi.org/10.1557/PROC-625-165

[11] Shortall A. C., Palin W. M., Burtscher P.: Refractive index mismatch and monomer reactivity influence composite curing depth. Journal of Dental Research, 87, 8488 (2008). https://doi.org/10.1177/154405910808700115

[12] Suzuki H., Taira M., Wakasa K., Yamaki M.: Refractive-index-adjustable fillers for visible-light-cured dental resin composites: Preparation of $\mathrm{TiO}_{2}-\mathrm{SiO}_{2}$ glass powder by the sol-gel process. Journal of Dental Research, 70, 883-888 (1991).

https://doi.org/10.1177/00220345910700050401

[13] Fujita K., Nishiyama N., Nemoto K., Okada T., Ikemi Y.: Effect of base monomer's refractive index on curing depth and polymerization conversion of photo-cured resin composites. Dental Materials Journal, 24, 403 408 (2005).

https://doi.org/10.4012/dmj.24.403

[14] Aloui F., Lecamp L., Lebaudy P., Burel F.: Relationships between refractive index change and light scattering during photopolymerization of acrylic composite formulations. Journal of the European Ceramic Society, 36, 1805-1809 (2016).

https://doi.org/10.1016/j.jeurceramsoc.2016.01.033
[15] Castagna R., Vita F., Lucchetta D. E., Criante L., Simoni F.: Superior-performance polymeric composite materials for high-density optical data storage. Advanced Materials, 21, 589-592 (2009). https://doi.org/10.1002/adma.200801822

[16] Park S-M., Oh C-Y., Jo N-J.: Fabrication and properties of glass cloth reinforced multifunctional acrylic polymer substrate. Polymer Bulletin, 73, 2485-2492 (2016). https://doi.org/10.1007/s00289-016-1676-5

[17] Meng Y., Tsai M., Schmidt G. R., Anthamatten M.: Gradient-index materials based on thiol-ene networks. ACS Applied Materials and Interfaces, 7, 8601-8605 (2015).

https://doi.org/10.1021/acsami.5b00650

[18] Asuncion M. Z., Krug D. J., Abu-Seir H. W., Laine R. M.: Facile thiol-ene reactions of vinyl $\mathrm{T}_{10} / \mathrm{T}_{12}$ silsesquioxanes for controlled refractive indices for transparent fiber glass reinforced composites. Journal of the Ceramic Society of Japan, 123, 725-731 (2015).

https://doi.org/10.2109/jcersj2.123.725

[19] Aloui F., Lecamp L., Lebaudy P., Burel F.: A numerical tool for studying photopolymerization inside thick composites: Influence of optical properties on the conversion profiles for a silica/TEGDMA-BisGMA formulation. Journal of Photochemistry and Photobiology A: Chemistry, 356, 418-424 (2018). https://doi.org/10.1016/j.jphotochem.2018.01.023

[20] Matsuda T., Funae Y., Yoshida M., Yamamoto T., Takaya T.: Optical material of high refractive index resin composed of sulfur-containing aliphatic and alicyclic methacrylates. Journal of Applied Polymer Science, 76, 45-49 (2000).

https://doi.org/10.1002/(SICI)10974628(20000404)76:1<45::AID-APP6>3.0.CO;2-M

[21] Hadis M. A., Tomlins P. H., Shortall A. C., Palin W. M.: Dynamic monitoring of refractive index change through photoactive resins. Dental Materials, 26, 1106-1112 (2010). https://doi.org/10.1016/j.dental.2010.07.011

[22] Howard B., Wilson N. D., Newman S. M., Pfeifer C. S., Stansbury J. W.: Relationships between conversion, temperature and optical properties during composite photopolymerization. Acta Biomaterialia, 6, 2053-2059 (2010). https://doi.org/10.1016/j.actbio.2009.11.006

[23] Koseki K., Sakamaki H., Jeong K-M.: In situ measurement of shrinkage behavior of photopolymers. Journal of Photopolymer Science and Technology, 26, 567-572 (2013).

https://doi.org/10.2494/photopolymer.26.567

[24] Lecamp L., Youssef B., Bunel C., Lebaudy P.: Photoinitiated polymerization of a dimethacrylate oligomer: 1 . Influence of photoinitiator concentration, temperature and light intensity. Polymer, 38, 6089-6096 (1997). https://doi.org/10.1016/S0032-3861(97)00184-5

[25] Mills N. J.: Optical properties. in 'Polymer science: A materials science handbook' (ed.: Jenkins A. D.) NorthHolland Publishing, Amsterdam, Vol 1, 489-535 (1972). 